\title{
STRESS INDUCED GROOMING IN THE RAT - AN ENDORPHIN MEDIATED SYNDROME
}

\author{
R.J. KAT"Z* and K.A. ROTH \\ Mental Health Research Institute, Department of Psychiatry, University of Michigan \\ Medical Center, Ann Arbor, MI 48109 (U.S.A.)
}

(Received February 13th, 1979)

(Revised version received March 29th, 1979)

(Accepted April 3rd, 1979)

\section{SUMMARY}

Exposure of adult male Sprague-Dawley rats to a non-traumatic noiselight stress procedure subsequently increased grooming behavior in a novel environment. The grooming syndrome was marginally facilitated by adrenalectomy and by hypophysectomy. Opiate blockade by naltrexone returned grooming to basal levels. This suggests that stress induced grooming is not dependent upon pituitary-adrenal integrity for its expression, although it may be modulated by the latter. On the other hand this form of grooming may depend upon an endogenous opiate system.

Grooming in the rat appears to be a useful behavioral assay for corticotropin related peptides $[3,5]$, substance $P$ related peptides [7], and possibly also opiates $[4,5]$. The major paradigms for its study include pharmacological induction of excessive grooming [5] and normal grooming as measured in well habituated animals under minimal stress $[3,14]$. The fact that grooming may in part depend upon ACTH-related peptides may indirectly point to a role for this behavior in stress and coping. While stress is well characterized as a psychoendocrine response it is considerably lesi well understood behaviorally, although changes have been noted in processes such as analgesia and possibly also memory consolidation for aversive stimulation $[8,9]$.

Given tine established involvement of ACTH related peptides in grooming. and the relatively limited behavioral characterization of stress we examined grooming in this regard. The stress related grooming syndrome was also analyzed through psychoendocrine manipulations to allow further comparison and contrast with other grocming and psychoendocrise related syndromes.

\footnotetext{
* To whom correspundence should be addressed.
} 
Eighty-nine adult Sprague -Dawley rats (Charles River Farms, Portage, MI), 60-70 days of age at the start of tes ing were group housed with food (T'eklad 4.0\% fat rodent diei S-0836) and tap water continuously available, ard norrnal $12 \mathrm{~h} / 12 \mathrm{~h}$ day/night cycles (light on $=08: 00-20: 00$ ). A total of ei wht groups were run in a factorial design in which the presence or absence of stress was varied across four conditions, these being a basal condition (i.e. no further manipulation), adrenalectomy, hypophysectomy and opiate blockade. Adrenalectomies were performed under barbiturate anesthesia within cur laboratory while hypophysectomies were performed by the supplier using ether anesthesia and a parapharyngeal approach. All surgery wws performed at least 2 weeks before testing to allow sufficient time for recovery. For both surgical groups a $0.9 \%$ sodium chloride solution was provicied to maintain normal health, and a daily fruit supplement was provided for hypophysectomized subjects for the same reason. Opiate blockade was obtained in the final two groups of subjects through the adr inistration of a low $(2 \mathrm{mg} / \mathrm{kg})$ dose of a specific and long lasting narcotic antagonist $(2 \mathrm{mg} / \mathrm{kg}$ of naltrexone $\mathrm{HCl}$; Endo Laboratories; administered intraperitoneally; $\mathrm{h}$ prior to testing. Although two reports suggest the possible existence of slight agonist effects for this drug at higher doses $[1,13]$, recent reports agree the primary classification of the drug is that of narcotic antagonist $[2,6,10]$ with any agonist effects being at best liminal Noagonisteffects have been identified in the rat at the dose and time presently employed.

Unstressed subjects for all four conditions were removed from group housing and placed immediately (i.e., $<30 \mathrm{sec}$ ) in a $1.44 \mathrm{~m}^{2}$ plexiglas open field for a single 12-min observation. To minimize stress during testing for all subjects testing was carried out in dim illumination (500 milliphoton red light which was subliminal for the subjects) with masking noise of $20-30 \mathrm{~dB}$ provided by an air circulation system. Stresaed subjects were exposed to the field under the same testing conditions after a $1 \mathrm{~h}$ exposure to $95 \mathrm{~dB}$ of white noise in a brightly ( $8 \times 70 \mathrm{~W})$ lit room. The dependent variable was grooming, which was scored as total seconds of flank grooming or facial grooming per 12-min session.

Results of the experiment are summarized in Table I as median scores and ranges.

Mann-Whitney U-tests were used to assess significance [12]. It is evident that stress significantly elevated normal grooming (first column). This was not affected remarkably by hypophysectomy (third column), and may have been marginally increased by adrenalectomy (second column). The latter change is at best suggestive of an adrenal effect, and is not significant. On the other hand the opiate blocker naltrexone virtually eliminated the effect at a dose which did not significantly reduce the level of normal grooming.

While the naltrexone reversal of the effect of stress upon grooming is evident both statistically and by the virtual identity of basal and stress scores, perhaps some additional comment is called for regarding the apparent 
TABLE I

BASAL AND STRESS-INDUCED GRDOMING IN THE RAT

Values expressed as sec/12 min observation period.

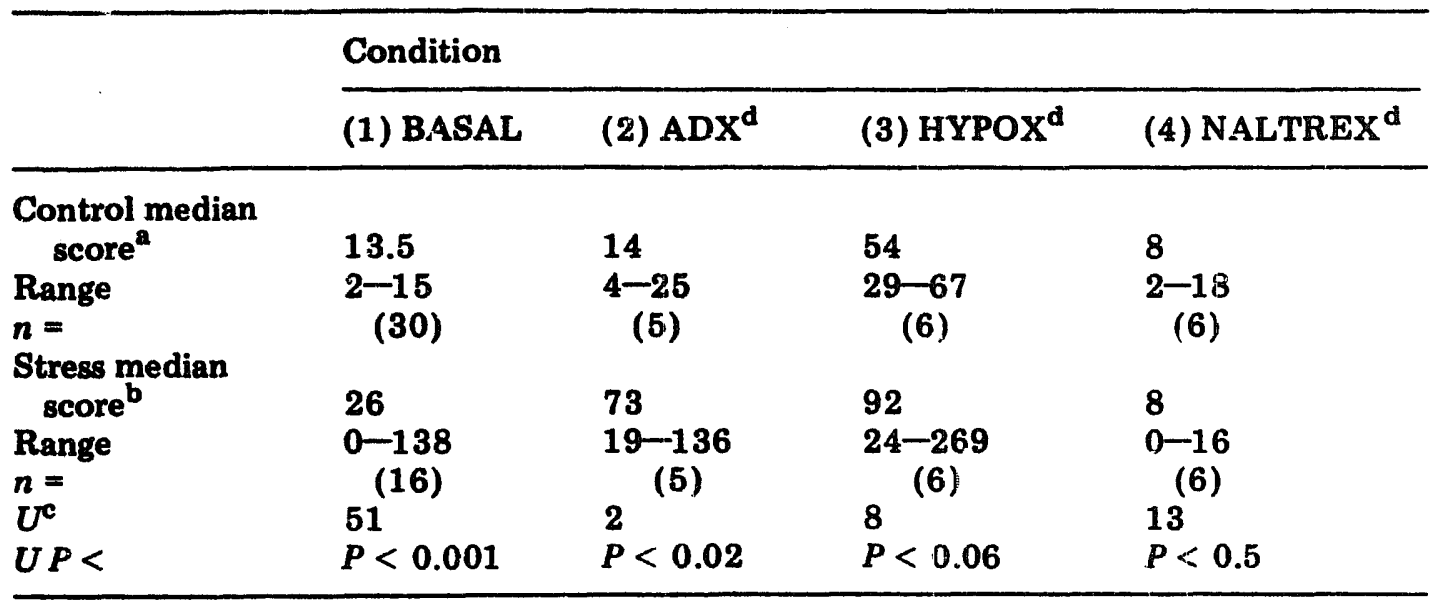

Comparison of all basal groups across ınanipulations indicates no significant difference for control vs. ADX, HYPOX, or NALTREX groups $(U=75,54,17$ respectively, $P<0.05)$. ${ }^{b}$ Comparison of all stress groups across manipulations indicates no significant difference for control vs. ADX or HYPOX $(U=23,5,67)$. Naltrexone treated group is significantly lower than stress control $(U=7.5, P<0.001)$.

${ }^{c}$ All $U$ scores in table are based upon control vs. stress $c$ smparison within conditions (columns).

ADX, adrenalectomized; HYPOX, hypophysectomized; NALTREX, Naltrexone treated.

increases in stress elicited grooming in the two other experimential groups in comparison with their respective stressed control. Both adrenalectomy and hypophysectomy produced supranormal increases in grooming in the stress condition. This is suggestive of a peripherally mediated modulation. However the lack of statistical significance limits this to speculation. Could this lack of significance then be a function of small sample size which otherwise might be significant? Several factors argue against this, including the extensive overlap of sample ranges across stress conaitions and the fact that crossstress comparisons all in fact had reasonably large $(>20)$ degrees of freedom due to comparison with t'،eir respective control. Finally it must be noted that significant increases were observed using even smaller degrees of freedom within conditions. A comparison of cross-stress conditions in fact indicates the only statistically significant change is a reduction in the naltrexone condition (see Table I, Note B).

While any contribution of pituitary-adrenal hormones cannot be entirely excluded (they may remain intact centrally [15] certainly at best a limited contribution of the pituitary or adrenal glands is suggested by the present findings. However, at least one determinant of these effects seems to be an endogenous opiate. The present results extend prior stuclies upon the role of 
opiates in stress related syndromes [9]. They are also consistent with previous reports of increased grooming after exogenous opiate [4]. We and others have suggested that stress may increase behavioral activation; grooming appears to be a useful index of this effect.

\section{ACKNOWLEDGEMENTS}

We are grateful to Kanen Erhardt for editorial assistance.

\section{REFERENCES}

1 Biumberg, H., Dayton, H.B. and Wolf, P.S., Analgesic and narcotic antagonist properties of noroxymorphone derivatives, Toxicol. Appl. Pharmacol., 10 (1967) 406.

2 Blumberg, H. and Dayton, H.B., Narcotic antagonist studies with EN 1639A (Ncyclopropylnoroxymorphone hydrochloride) V Int. Congr. Pharmacol., (abstr.) $1972,23$.

3 Dunn, A.J., Green, E.J. and Issacson, R.L., Intracerebral adrenocorticotropic hormone mediates novelty induced grooming in the rat, Science, 203 (1979) 281-283.

4 Fog, $R$., Behavioral effects in rats of morphine and amphetamine and of combination of the two drugs, Peychopharieacologia (Berl.), 16 (1970) 305-312.

5 Gispen, W.H., Reith, M.E.A., Schotmar, P., Wiegant, X.M., Zwiers, H. and DeWied, D., CNS and ACTH-like peptides: neurochemical response and interaction with opiates.

In L.H. Miller, C.A. Sandman and A.J. Kastin (Eds.), Neuropeptide Influences on the Brain and Behavior, Vol ume 17, Advanc. Biochem. Psychopharmacol., Raven, New York, 1977, pp. 61-80.

6 Jaffe, J.H. and Martin, W.R., Narcotic analgesics and antagonists. In L.S. Goodman and A. Gilman (eds.), The Pharmacological Basis of Therspeutics, 5th edn, MacMillan, New York, 1975, pp. 245-283.

7 Katz, R.J., Central injection of substance $P$ elicits grooming behavior and motor inhibition, Neurosci. Lett., 12 (1979) 133-136.

8 Klein, S.B., Adrenal-pituitary influence in reactivation of avoidance learning memory in the rat after intermedliate intervals, J. comp. physiol. Psychol., 79 (1972) 341357.

9 Madden, I.V.J., Aki, H., Patrick, R.L. and Barchas, J.D., Stress-induced parallel changes in central opioid levels and pain responsiveness in the rat, Nature (Lond.), $265(1977) 358-860$.

10 Martin, W.R., Jasinski, J.R. and Mansky, P.A., Naltrexone, an antagonist for the treatment of heroin dependance, Arch. gen. Psychiat., 28 (1973) 784-791.

11 Selye, H., The evolution of the stress concept, Amer. Scientist, 61 (1973) 692-699.

12 Siegel, S., Nonparametric Statistics for the Behsvioral Sciences, McGraw Hill, New York, 1956, 312 pp.

13 Verebey K., Volapka, J. and Mule, 8.J., Naltrexone disposition metabolism, and effects after acute and chronic dosing, Clin. Pharmacol. Ther., 20 1976) 315-328.

14 Walsh, R.N. and Cummins, R.A., The open field test - a critical r sview, Psychol. Rev., 83 (1976) 482-504.

15 Watson, S.J., Akil, H., Richard, E.W. II and Barchas, J.D., Evidence for iwo separate oplate peptide neuronal systems, Nature (Lond.), 285 (1978) 226-269. 